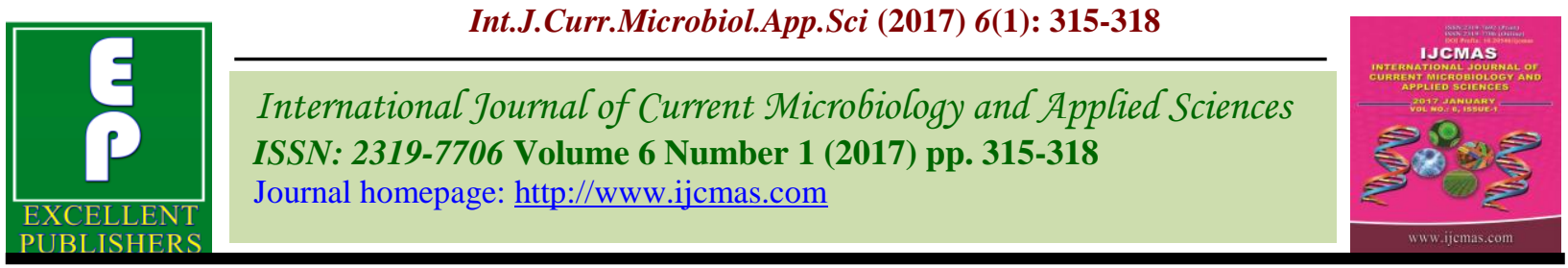

Original Research Article

http://dx.doi.org/10.20546/ijcmas.2017.601.038

\title{
Rare Case of Trichosporon mucoides Skin Infection in an Immuno-competent Patient
}

\author{
Dudhat Vaibhav L*, Maithili Kavathekar and Sonal Patil \\ Department of Microbiology, Microbiology and HIC, Sahyadri Speciality Labs, Pune, India \\ *Corresponding author
}

\author{
A B S T R A C T
}

Keywords

Trichosporon

mucoides,

Skin Infection

Article Info

Accepted:

18 December 2016

Available Online:

10 January 2017

Trichosporon spp. are ubiquitous fungi and form normal flora on skin and gastrointestinal tract of humans. There are at least nine Trichosporon species that are potentially pathogenic to humans. A 29 year old male visited our lab for skin scraping and examination of diffuse de-pigmented patches over both soles associated with scaling for more than a month. Skin scraping was done from both the soles. On direct $\mathrm{KOH}$ mount, budding yeast cells with hyphae were seen, suggestive of yeast like fungus. The culture growth was identified as T. mucoides by VITEK2 (Biomerieux) and based on cultural morpholopgy, microscopy and biochemical reactions. The patient was treated with oral fluconazole (200 $\mathrm{mg}$ qid). The lesions showed improvement. T. mucoides needs to be considered in differential diagnosis in such cases.

\section{Introduction}

Trichosporon spp. are ubiquitous yeast-like fungi found in water and soil. They are found as the normal flora on skin and gastrointestinal tract of humans (Capoor et al., 2015; Sageerabanoo et al., 2011). Previously, the species Trichosporon beigelii was used to represent all the pathogenic members of the genus Trichosporon. More recently, this species has been divided into several distinct species, based on morphological characteristics, biochemical reactions and molecular studies. There are at least 9 Trichosporon species that are potentially pathogenic to humans: T. asahii, T. mucoides, T. cutaneum, T. inkin, $T$. ovoides, T. asteroids, T. loubieri, T. pullulans, and $T$. japonicum. Out of these, T. asahii and
T. mucoides have potential to cause severe life-threatening infections whereas the others usually cause superficial infections (Ağirbasli et al., 2008).

A few cases of Trichosporon mucoides as a cause of onychomycosis and other infections including disseminated fungemia have been published (Capoor et al., 2015; Sageerabanoo et al., 2011; Ağirbasli et al., 2008; Nettles et al., 2003; Padhi et al., 2014).

We report an unusual case of superficial skin infection on the soles of a 29 years old immuno-competent male caused by $T$. mucoides. 


\section{Case Report}

A 29 year old male visited our lab for skin scraping and examination of diffuse depigmented patches over both soles associates with scaling for more than a month.

When enquired about the related history and his lifestyle, it was learnt that the patient was often involved in outdoor sports and camping and trekking. He also has a tendency to sweat a lot. About a month and a half ago, he had gone on trekking to a near fort and had shoes on for almost a complete day. He noted scaly de-pigmented lesions on soles a week after this event.

Skin scraping was done from both the soles. On direct $\mathrm{KOH}$ mount, budding yeast cells with hyphae were seen, suggestive of yeast like fungus. Sample was cultured on Sobbauraud's dextrose agar with and without antibiotic (Chloramphenicol). After 48 hours of incubation, creamy, white smooth colonies were obtained, which were positive for urea hydrolysis and identified as T. mucoides by VITEK2 (Biomerieux) and based on cultural morpholopgy, microscopy and biochemical reactions.
The patient was treated with oral fluconazole (200 mg qid) and asked for follow up after two weeks. The lesions showed improvement. $\mathrm{He}$ was asked to continue treatment for another two weeks and follow up.

\section{Results and Discussion}

T. mucoides is currently included in the clade of T. cutaneum. T. mucoides is a more frequent cause of infections like onychomycosis as compared to other Trichosporon species according to studies carried out by The' rizol-Ferly et al. (The' rizol-Ferly et al., 1994; The' rizol-Ferly et al. b, 1994). Trichosporon mucoides has been reported from several cases of kidney, heart and liver transplant recipients (Nettles et al., 2003, Lacasse and Cleveland, 2009), premature newborns with deep infections (Go“kahmetoglu et al., 2002; Silva et al., 2004), peritoneal dialysis patients (Chen et al., 2013), leukemic (Kendirli et al., 2006) and diabetics(The' rizol-Ferly et al., 1994).

The risk factors for infections T. mucoides include admission to an intensive care unit, antibiotic therapy, and the presence of a central venous catheter (Silva et al., 2004).

Fig.1 Diffuse depigmented scaling lesion on right foot (Sole)

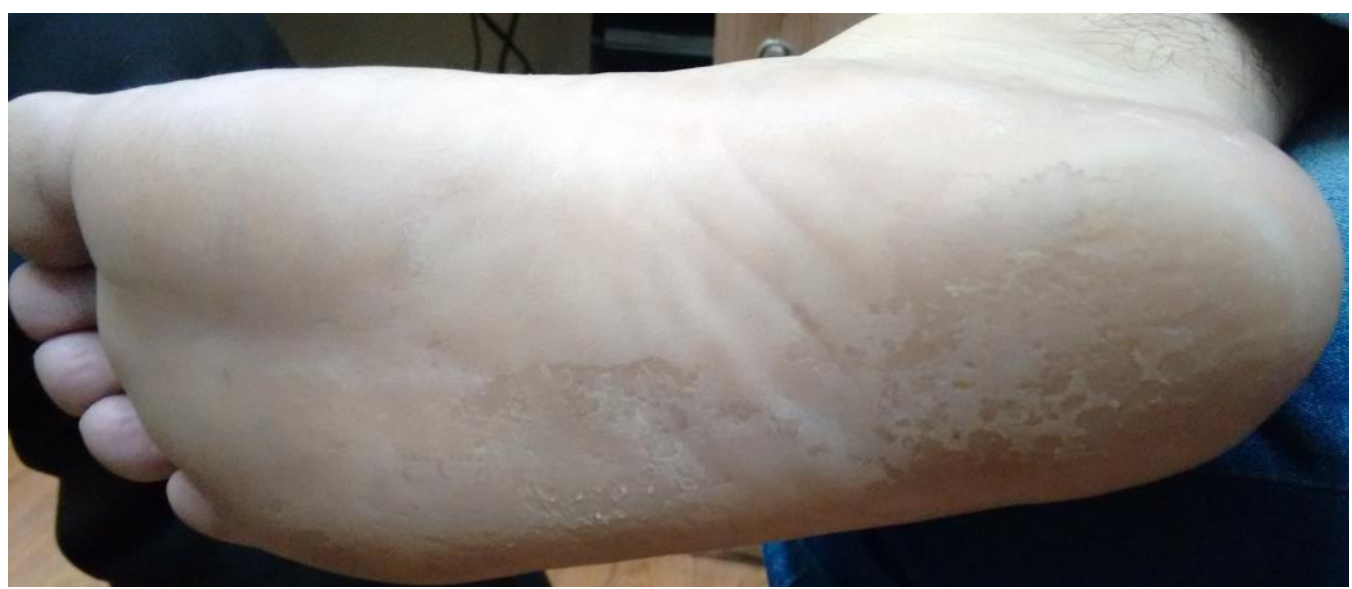


Fig.2 Creamy white colonies of $T$. mucoides on SDA

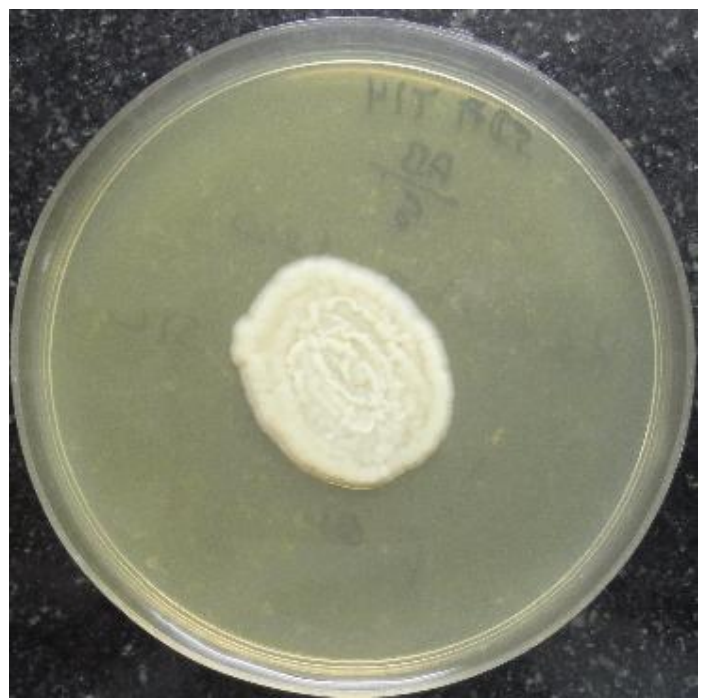

Fig.3 Rectangular arthroconidia of T. mucoides in corn meal agar

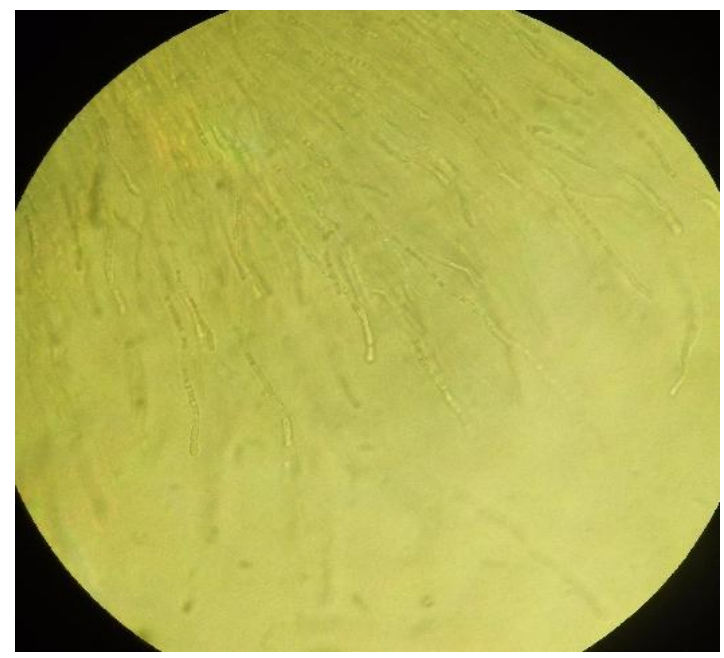

Other predisposing factors include genetic abnormalities, low socioeconomic level, old age, hyperhydrosis, climatic conditions, diabetes, immunodeficiency, atherosclerosis, and trauma (Capoor et al., 2015). Optimal therapy for Trichosporon infection is poorly defined (Nettles et al., 2003). At present, there are no therapeutic guidelines for treatment of systemic infections $T$. mucoides. Low level resistance has been reported against itraconazole and fluconazole (4\% and $6 \%$ respectively) however amphotericin $\mathrm{B}$ showed $100 \%$ sensitivity (Kendirli et al.,
2006). The outcome of the infection more often than not depends on the immune status of the host and the extent of the infection. Most cases of disseminated Trichosporon infection have been treated with amphotericin $\mathrm{B}$, at times in combination with 5fluorocytosine. This combination appears to have limited activity against Trichosporon fungi. Data regarding regarding the utility of lipid formulations of amphotericin is limited. On the other hand, there is growing evidence in support of use of azoles for treatment of Trichosporon infections (Anaissie et al., 
1992). The most common fluconazole dosage used was $400 \mathrm{mg}$ per day (range, 100-400 $\mathrm{mg}$ ) for 2-26 weeks. These patient was treated with oral fluconazole (200 mg qid) and showed evidence of improvement after 15 days. The plan of treatment is to continue with oral fluconazole for another 6-8 weeks with follow up after every 2 weeks.

In conclusion, T. mucoides, though a rare entity causing superficial skin infections, needs to be considered as a differential diagnosis in such cases.

\section{References}

Ağirbasli, H., Bilgen, H., Ozcan, S.K., Otlu, B., Sinik, G., Cerikçioğlu, N., et al. 2008. Two possible cases of Trichosporon infections in bone marrow-transplanted children: The first case of $\mathrm{T}$. japonicum isolated from clinical specimens. Jpn. J. Infect. Dis., 61: 130-2.

Anaissie, E., Gokaslan, A., Hachem, R., et al. 1992. Azole therapy for trichosporonosis: clinical evaluation of eight patients, experimental therapy for murine infection, and review. Clin. Infect. Dis., 5: 781-7.

Capoor, M.R., Agarwal, S., Yadav, S., Saxena, A.K., Ramesh, V. 2014. Trichosporon mucoides causing onychomycosis in an immunocompetent patient. Int. J. Dermatol., 54: 704-7.

Chen, Y.T., Yang, W.C., Chen, T.W., Lin, C.C. 2013. Trichosporon mucoides peritonitis in a continuous ambulatory peritoneal dialysis patient. Perit. Dial. Int., 33: 341-2.

Go"kahmetog lu, S., Nedret Koc , A., Gu“ nes, T, Cetin, N. 2002. Case reports. Trichosporon mucoides infection in three premature newborns. Mycoses, 45: 123-5.
Kendirli, T., Ciftc I, E., Ince, E., Oncel, S., Dalgic,, N., Gu" riz, H., et al. 2006. Successful treatment of Trichosporon mucoides infection with lipid complex amphotericin B and 5- fluorocytosine. Mycoses, 49: 251-3.

Lacasse, A., Cleveland, K.O. 2009. Trichosporon mucoides fungemia in a liver transplant recipient: case report and review. Transpl. Infect. Dis., 11: 155-9.

Nettles, R.E., Nichols, L.S., Bell-McGuinn, K., Pipeling, M.R.., Scheel, P.J., Merz, W.G. 2003. Successful Treatment of Trichosporonmucoides Infection with Fluconazole in a Heart and Kidney Transplant Recipient. Clin. Infect. Dis., 36: 63-66.

Padhi, S., Dash, M., Pattanaik, S., Sahu, S. 2014. Fungemia due to Trichosporon mucoides in a diabetes mellitus patient: A rare case report. Indian J. Med. Microbiol., 32: 72-4.

Sageerabanoo, Malini, A., Oudeacoumar, P., Udayashankar, C. 2011. Onychomycosis due to Trichosporon mucoides. Indian $J$. Dermatol. Venereol. Leprol., 77: 76-7.

Silva, V., Di'az, M.C., Febre,' N., Chilean Invasive Fungal Infections Group. Invasive fungal infections in Chile: a multicenter study of fungal prevalence and susceptibility during a 1-year period. Med Mycol., 42:333-9.

The' rizol-Ferly, M., Kombila, M., Gomez de Diaz, M., Duong, T.H., Richard-Lenoble, D. 1994. White piedra and Trichosporon species in equatorial Africa. I. History and clinical aspects: an analysis of 449 superficial inguinal specimens. Mycoses, 37: 249-53. 7.

The' rizol-Ferly, M., Kombila, M., Gomez de Diaz, M., Douchet, C., Salaun, Y., Barrabes, A., et al. 1994. White piedra and Trichosporon species in equatorial Africa. II. Clinical and mycological associations: an analysis of 449 superficial inguinal specimens. Mycoses, 37: 255-60.

\section{How to cite this article:}

Dudhat Vaibhav, L., Maithili Kavathekar and Sonal Patil. 2017. Rare Case of Trichosporon mucoides Skin Infection in an Immuno-competent Patient. Int.J.Curr.Microbiol.App.Sci. 6(1): 315-318. doi: http://dx.doi.org/10.20546/ijcmas.2017.601.038 